\title{
MUDANÇAS RECENTES NAS RELAÇÕES INTERSETORIAIS: UM EXAME DAS ATIVIDADES DE SERVIÇO E INDUSTRIAIS
}

\author{
Vinicius Fornari, Rogério Gomes e Celio Hiratuka
}

Resumo: Este estudo examina as mudanças ocorridas nas últimas décadas nos vínculos entre as diferentes atividades da economia, especialmente nos elos entre as atividades de serviços e industriais. Para esse exame, analisamos os vínculos (direções) e as intensidades (valor) das relações intersetoriais na economia brasileira e de outros países em 1995 e 2010. A pesquisa está estruturada em dois pontos básicos: 1) revisão das abordagens teóricas sobre a evolução e os vínculos entre as atividades industriais e de serviços na economia, e; 2) indicadores estimados a partir da combinação da metodologia de análise de redes (software Pajek) com dados da matriz insumo-produto (WIOD, 2014). Os resultados indicam que existe uma relação sistêmica entre a indústria e serviços nos países que adensaram a estrutura produtiva.

Palavras chave: relações intersetoriais; atividades industriais e de serviços; análise de redes; matriz insumo-produto.

\begin{abstract}
This study examines the changes in recent decades in the links between the different activities of the economy, especially in those links between manufacturing and services. This research seeks to analyze the linking (directions) and the intensities (value) of the intersectorial linkages in Brazilian economy from 1995 and 2010. The research is structured into two basic points: 1) A review of the theoretical approaches concerning the evolution and the linkage between industrial activities and services in economic, and 2) developing indicators using a combination between the network analysis methodology (Pajek software) and input-output matrix data (WIOD, 2014). Furthermore, we demonstrated that in most countries, the relationship between manufacturing and services are the main components of the network density, quantifying the importance of this relationship in the productive structure.
\end{abstract}

Keywords: intersectorial linkages; service sectors; network analysis; input-output matrix.

Classificação JEL: O14, O20, O25. 


\section{Introdução}

Os estudos que investigam as fontes e impactos do desenvolvimento econômico por meio das relações intersetoriais não são recentes. Em particular, as teorias dos anos 1950 utilizaram os setores industriais e os seus encadeamentos para avaliar e/ou explicar as diferenças nos processos de desenvolvimento em diferentes países/regiões. Alguns desses estudos discutiram também a importância do processo de industrialização e seus transbordamentos para o desenvolvimento econômico (PREBISCH, 1949; HIRSCHMAN, 1958; KALDOR, 1967; THIRLWALL, 2005).

Hirschman (1958, cap 3; 1983: 15), por exemplo, contesta o pressuposto da teoria "tradicional” de que o desenvolvimento é equilibrado e de que a industrialização seria fenômeno meramente associado ao crescimento simultâneo de muitas atividades relacionadas e às escalas produtivas. Para o autor, essa estratégia de crescimento simultâneo é inviável, especialmente em economias em desenvolvimento pela existência de elos não desenvolvidos ("buracos”) no tecido industrial. Nesse sentido, para cada situação (país/região) seria necessário selecionar setores com capacidade de promover transbordamento benéficos para o restante da estrutura produtiva, ou seja, incentivar aquelas indústrias mais capazes de impulsionar e/ou induzir os investimentos em outras.

Hirschman (1958, cap 6), propõe avaliar as interdependências e os impactos da expansão de uma indústria sobre o restante da economia, ou seja, identificar as capacidades de gerar e propagar efeitos por meio dos mecanismos de indução. A percepção desses mecanismos permite ao autor desenvolver o conceito de efeito em cadeia (linkage) para avaliar os encadeamentos do investimento de cada setor de uma economia “que são postos em ação através das relações de insumo-produção” (HIRSCHMAN, 1977; 12).

O objetivo deste estudo não é a propriamente a discussão sobre mecanismos de fomento ou indução do crescimento ou desenvolvimento econômico, mas resgatar alguns dos conceitos e dos princípios metodológicos implícitos nessas abordagens (intensidades das relações, efeitos de encadeamentos, investimentos induzidos por cada setor) para discutir as mudanças recentes nas interações entre as diferentes atividades da economia.

Nas últimas décadas, o setor de serviços tem ampliado o seu papel nas cadeias internacionais de valor e a sua importância nas economias nacionais (OCDE,2013). Em muitos países, inclusive em economias com renda per capita média como a brasileira, a 
participação relativa dessas atividades no PIB superou as demais. Entretanto, parcela das mudanças recentes nas estruturas das economias nacionais não parece atrelada unicamente às etapas do desenvolvimento econômico como defendido por alguns autores.

Assim, este estudo busca examinar as mudanças ocorridas nas últimas décadas nos vínculos entre as diferentes atividades da economia, especialmente nos elos entre as atividades de serviços e industriais. Para examinar esta "reestruturação", o estudo analisa as relações intersetoriais entre os setores na economia de países em diferentes estágios de desenvolvimento. Como método, empregamos: (1) a análise descritiva dos coeficientes de demanda intermediária das doze maiores economias do mundo (segundo o PIB de 2011: Alemanha, Brasil, China, Coréia, EUA, França, Índia, Itália, Japão, México, Reino Unido e Rússia) para os anos de 1995 e 2010, disponíveis no World Input-Output Database (WIOD, 2014); (2) examinamos as intensidades (valor) e as direções das relações nos diferentes setores das economias selecionadas por meio de Análise de Redes (software Pajek) aplicada sobre as matrizes de insumo-produtos.

Com esse intuito, tendo como referência a "hipótese dos três setores”, a seção 2 revisita os principais aspectos apontados pela literatura para explicar as mudanças na participação das atividades de serviços. Na seção seguinte apresentamos os índices de participação do valor do consumo intermediário para os agregados Serviços, Indústria, Recursos Naturais e Construção. A seção 4, complementar à anterior, trata dos indicadores desenvolvidos a partir do método de rede para analisar as estruturas produtivas internas desses países e quantificar a importância das relações intersetoriais. Os comentários finais são apresentados na quinta seção.

\section{A hipótese dos três setores e a participação das atividades de serviços}

A hipótese dos três setores consiste em avaliar a participação das atividades primária (produção agrícola e extração mineral), secundária (bens de consumo e investimentos ligados aos setores industrial e de construção) e terciária (atividades de serviços) por meio, entre outros, do nível de empregos e/ou do valor adicionado a longo do processo de desenvolvimento econômico. É suposto que nesse processo há uma progressão gradual, frequentemente coligado ao nível da renda per capita: (1) nos primeiros estágios, o predomínio é do setor primário tanto em termos de emprego e de criação de riqueza; (2) a expansão desta atividade incita o setor secundário, que progressivamente ganha importância e passa a "sustentar" o crescimento dos demais setores, seja pela demanda de insumos, seja pela transferência de progresso técnico incorporada nos produtos fornecidos; 
(3) o desenvolvimento das atividades industriais estimula o setor terciário que terminam por concentrar a maior parte do emprego e do valor adicionado. Esse padrão, que associa atividade “dominante” e estágio de desenvolvimento, foi observado primeiramente por Fisher (1935) e Clark (1940), e, posteriormente, analisados nos trabalhos de Kuznets (1957 e 1966) e Kongsamut et al. (2001) para a economia dos EUA.

Na literatura, há três abordagens principais que procuram explicar o aumento da participação dos serviços na economia: i) mudança na estrutura da demanda final decorrente do aumento da renda e, consequentemente, no consumo de bens do setor de serviços; ii) o diferencial de produtividade entre o setor terciário e os industriais, e; iii) a crescente especialização do setor de serviços que favorece a terceirização - por vezes, a transferência - de certas atividades (SCHETTKAT e YOCARINI, 2003).

Em relação às mudanças na estrutura de consumo, Fisher (1935) e Clark (1940) entendem que a demanda se desloca para serviços pela saturação do consumo relativo a bens industriais. No entanto, para Katouzian (1970) as avaliações empíricas mostram formas variadas de crescimento da demanda entre os diferentes tipos serviços. O autor classifica os setores de serviços em três tipos: novos, velhos e complementares. Os primeiros são aqueles que apresentam grande variação na demanda com o advento do “consumo em massa”, ou seja, quando o crescimento no consumo parece decorrer do aumento da renda per capita e do tempo de lazer ${ }^{1}$. Os velhos serviços são aqueles que a demanda passada decorre de uma distribuição menos equitativa da renda, bem como da relativa ausência de alternativas de emprego - caso, por exemplo, dos serviços domésticos no Brasil. Com o desenvolvimento e o aumento dos salários, esses serviços são continuamente substituídos por bens de consumo duráveis e os novos serviços. Por fim, a demanda por serviços complementares está diretamente ligada com a ascensão da indústria, ao crescimento de bens intermediários, a unificação dos mercados nacional e internacional, a burocratização e urbanização. Estes serviços devem crescer enquanto existirem diferentes oportunidades tecnológicas e, por isso, caracterizam-se por serem mais concentrados no tempo.

Por outro lado, a tese sobre o diferencial de produtividade entre os setores de serviços e industriais não resulta do aumento da demanda por serviços, mas do crescimento

\footnotetext{
${ }^{1}$ Não obstante, inexistem razões a priori para esperar que o uso intensivo de capital (automação) leve ao crescimento da demanda por esses serviços.
} 
assimétrico das produtividades setoriais. Para Baumol $(1967)^{2}$, a produtividade do trabalho no setor industrial cresce mais rápido do que nos serviços em virtude do grande número de inovações de processo, principalmente em máquinas e equipamentos. Comparadas com as industriais, as atividades de serviços não sustentam isoladamente aumentos constantes e cumulativos da produtividade derivada da acumulação de capital, inovação de processo ou economias de escala. Essa característica, que limita as inovações poupadoras de mão-deobra, torna a produtividade do terciário comparativamente inferior no longo prazo (BAUMOL, 1967; 420) ${ }^{3}$.

Ademais, destaca o autor, a participação do emprego no setor de serviços será maior em economias de alta renda, pois, se a variação no salário está alinhada com taxa média de crescimento da economia, então a parcela dos serviços na produção nominal também irá aumentar com a renda. Entretanto, esse aumento não é reflexo da demanda por serviços, mas sim da relativa "estagnação tecnológica" na produção de serviços. Em suma, as diferenças nas produtividades induzem o "deslocamento natural" do trabalho das atividades industriais e promovem o crescimento mais que proporcional do emprego e da renda agregada nas atividades de serviços, sem ser, no entanto, o setor de maior produtividade.

Baumol et. al (2012, cap 9) descreve as inovações da IBM em termos de "serviços prestados às empresas” para demonstrar que o ganho de produtividade desses setores proporciona ganhos ainda maiores de produtividade nos setores industriais, como no caso das novas tecnologias de informação e telecomunicações. Nesse sentido, não apenas o diferencial de produtividade se mantém ou é reforçado, mas cria fatores que elevam os custos dos serviços em relação aos dos bens industriais - que o autor denomina por “doença do custo”.

A última das três abordagens que visam explicar o aumento da participação das atividades de serviços na economia trata da interação dessas atividades e os setores industriais - objeto de exame por meio de indicadores nas próximas seções. O principal argumento dessa vertente é que a crescente especialização dos serviços favorece a terceirização - e/ou desverticalização - dessas atividades por parte dos setores industriais similar aos serviços complementares da tipologia de Katouzian (1970). No passado, muitas

\footnotetext{
${ }^{2}$ Essa tese é defendida primeiramente nos estudos de Baumol e Bowen (1966) e aprimorada nos artigos de Baumol (1967), Baumol et al (1985) e Baumol (2001 e examinada empiricamente para a economia americana nos estudos de Fuchs (1968) e Summers (1985).

${ }^{3}$ Para Baumol et al. (1985), em muitos casos a produtividade do terciário estagna depois de um dado período. Há também a questão da qualidade dos serviços oferecidos, pois o processo de redução de custos via salários, pode aprofundar a contratação de profissionais menos qualificados (BAUMOL, 1967; 422).
} 
dessas atividades eram realizadas pelas próprias firmas (contabilidade, jurídico, propaganda, segurança, alimentação, informática, comunicações, etc), mas foram sendo transferidas aos fornecedores visando a redução de custos.

Algumas dessas atividades foram embarcadas nos produtos industriais, ou seja, “os bens e serviços estão se combinando por meio de uma relação cada vez mais sinergética e simbiótica para formar um terceiro produto que nem é um bem industrial tradicional, nem tampouco um serviço convencional” (ARBACHE, 2015; 566). Essas relações tornam ainda mais difícil a análise das mudanças estruturais por meio do valor adicionado e números de trabalhadores entre indústria e serviços.

Finalmente, deve-se fazer referência ao fato de que alguns dos aspectos acima estão presentes em estudos que entendem desindustrialização como um processo inerente ao desenvolvimento econômico, ou seja, como um o fenômeno natural e benéfico das economias que seguem as "etapas dos três setores” (SINGH, 1987; ROWTHORN e RAMASWANY, 1999; PALMA, 2005; TREGENNA, 2008). No entanto, quando esse mesmo fenômeno é analisado para economias "menos avançadas", como é o caso brasileiro nas últimas décadas (FEIJÓ e CARVALHO, 2007; NASSIF, 2008; BRESSERPEREIRA e MARCONI, 2010; CANO, 2012), não há consenso sobre tais “benefícios” ou a "naturalidade" daquele processo. Mesmo reconhecendo a importância do debate, este estudo não o tem como foco, embora algumas das questões aqui analisadas possam contribuir para a sua discussão

\section{Analise das interações setoriais pela ótica do consumo intermediário}

Esta sessão avalia as demandas e ofertas intermediárias intersetoriais dos quatro agregados (recursos naturais, indústria, serviços e construção) para as doze maiores economias mundiais. A Tabela 1 apresenta o percentual do consumo intermediário da atividade $\mathrm{i}(\mathrm{i}=1,4)$ no total desse consumo do país $\mathrm{j}(\mathrm{j}=1,12)$ no ano $\mathrm{k}$ (1995 e 2010). A tabela permite a análise em três dimensões: i) mudanças nas características estruturais de cada economia (variação dos coeficientes nos dois anos); ii) similaridades nas demandas intermediárias por atividade (semelhanças nos coeficientes dos diferentes países); iii) explicitar a oferta e demanda agregadas da indústria e serviços (oito últimas linhas; 
hipótese dos “três setores”). Adicionalmente, mostramos as médias da amostra para cada um desses itens e o coeficiente de variação $(\mathrm{CV})^{4}$ por ano (quatro últimas colunas).

A Tabela 1 não permite admitir uma tendência internacional de redução da importância da indústria na economia. As mudanças nas estruturas de demanda e oferta intermediárias entre 1995 e 2010 possibilitam dividir as economias selecionadas em quatro casos distintos: (1) EUA e Reino Unido tiveram, de fato, a participação da demanda e oferta intermediárias da indústria reduzidas de forma significativa - cerca de -27\% e acima de $-40 \%$, respectivamente, para ambos os fluxos; (2) em algumas nações, como Itália (15\% e -21\%), México (cerca de -10\% e -12\%), Índia (-11\% e -4\%) e Brasil (-4\% e -8\%), as participações diminuíram de forma bem menos expressiva; (3) economias em que a as compras e vendas intermediarias da indústria tiveram variação positiva - Coréia (10\% e 18\%), França (10 e 4\%); (4) países com efeitos opostos na demanda e oferta intersetoriais - Alemanha (5\% e -23\%), Rússia (-3,5 e 10\%), Japão (1,3\% e - 4\%) e China (-3,2 e 3,5\%). Esses movimentos explicam a pequena variação negativa nos percentuais médios e permitem confirmar a importância das demandas e ofertas intersetoriais da indústria nas economias - superiores a $40 \%$ e $30 \%$, respectivamente.

Por outro lado, exceto para a Coréia $(0,7 \%$ e $-6 \%)$ e França $(-5,4 \%$ e 2,4$)$, as variações nas demandas e ofertas intersetoriais dos serviços foram positivas ${ }^{5}$, caracterizando o reforço generalizado das atividades terciárias como insumo para as atividades econômicas, mas, em especial, para a própria atividade. Todavia, se a demanda da indústria por bens e serviços é, em geral, superior à sua oferta, esta relação se inverte no caso dos serviços. Em outras palavras, se a indústria fomenta, o terciário depende da demanda dos demais agregados.

Os resultados anteriores refletem algumas características nacionais: (1) países que passaram por reforma estrutural profunda (forte reestruturação industrial e concomitante expansão de atividades do terciário de alto valor adicionado) - grupo 1 acima; (2) em razão do crescimento da renda e das atividades de serviços (hipótese dos três setores) e da concorrência externa, economias que a indústria teve participação reduzida - grupo 2; (3) países que promoveram mudanças visando manter o papel de produtor de certos bens

\footnotetext{
4 O coeficiente de variação de Pearson (CV), percentual entre o desvio padrão e a média, permite comparações entre variáveis de naturezas distintas e fornece ideia de precisão dos dados. Considera-se que quanto menor o $\mathrm{CV}$, mais homogêneos serão os dados e menores a variação do acaso.

5 No conjunto, os nossos comentários justificam a relativa homogeneidade da amostra (coeficiente de variação em torno de $25 \%$ ) e a maior heterogeneidade dos coeficientes da indústria.
} 
industriais e serviços - França, Alemanha; (4) economias que reafirmaram o papel da sua indústria - Coréia e China (maiores percentuais para a indústria). 


\begin{tabular}{|c|c|c|c|c|c|c|c|c|c|c|c|c|c|c|c|c|c|c|c|c|c|c|c|c|c|c|c|c|}
\hline \multirow[b]{2}{*}{ Demanda de } & \multicolumn{2}{|c|}{ EUA } & \multicolumn{2}{|c|}{ Reino Unido } & \multicolumn{2}{|c|}{ Alemanha } & \multicolumn{2}{|c|}{ Itália } & \multicolumn{2}{|c|}{ França } & \multicolumn{2}{|c|}{ Japão } & \multicolumn{2}{|c|}{ Rússia } & \multicolumn{2}{|c|}{ Coréia } & \multicolumn{2}{|c|}{ Índia } & \multicolumn{2}{|c|}{ Brasil } & \multicolumn{2}{|c|}{ China } & \multicolumn{2}{|c|}{ México } & \multicolumn{2}{|c|}{1995} & \multicolumn{2}{|c|}{2010} \\
\hline & 1995 & 2010 & 1995 & 2010 & \begin{tabular}{|c|}
1995 \\
\end{tabular} & 2010 & \begin{tabular}{|l|l|}
1995 \\
\end{tabular} & 2010 & 1995 & 2010 & 1995 & \begin{tabular}{|l|}
2010 \\
\end{tabular} & 1995 & \begin{tabular}{|l|}
2010 \\
\end{tabular} & 1995 & 2010 & 1995 & 2010 & 1995 & 2010 & 1995 & 2010 & \begin{tabular}{|l|}
1995 \\
\end{tabular} & 2010 & Média & $\mathrm{CV}$ & Média & $\mathrm{CV}$ \\
\hline \multicolumn{29}{|l|}{ Recursos Naturais por } \\
\hline Recursos Naturais (1) & 0.0 & 0.0 & 0.0 & 0.0 & 0.0 & 0.0 & 0.0 & 0.0 & 0.0 & 0.0 & 0.0 & 0.0 & 0.1 & 0.0 & 0.0 & 0.0 & 0.0 & \begin{tabular}{l|l}
0.0 \\
\end{tabular} & 0.0 & 0.1 & 0.2 & 0.0 & 0.0 & 0.0 & \begin{tabular}{l|l}
0.0 \\
\end{tabular} & 148.1 & 0.0 & 129.0 \\
\hline Serviços (2) & 1.9 & 1.9 & 2.2 & 1.6 & 1.8 & 1.4 & 1.2 & 1.1 & 2.4 & 1.9 & 1.1 & 0.9 & 7.7 & 5.7 & 0.8 & 0.7 & 3.1 & 2.6 & 2.6 & 3.9 & 3.1 & 2.4 & 3.5 & 3.8 & 2.6 & 68.9 & 2.3 & 63.7 \\
\hline Indústria (3) & 1.1 & 1.4 & 1.1 & 0.4 & 1.0 & 0.5 & 0.8 & 0.6 & 1.4 & 1.2 & 0.9 & 1.1 & 3.9 & 3.0 & 1.9 & 1.5 & 2.6 & 1.7 & 2.5 & 3.3 & 5.8 & 3.8 & 2.6 & 2.2 & 2.1 & 69.4 & 1.7 & 65.3 \\
\hline Construção (4) & 0.1 & 0.2 & 0.3 & 0.1 & 0.1 & 0.0 & 0.0 & 0.0 & 0.1 & 0.0 & 0.0 & 0.0 & 0.1 & 0.0 & 0.0 & 0.0 & 0.3 & 0.5 & 0.0 & 0.1 & 0.0 & 0.0 & 0.0 & 0.0 & 0.1 & 105.4 & 0.1 & 135.5 \\
\hline \multicolumn{29}{|l|}{ Serviços por } \\
\hline Recursos Naturais (5) & 0.8 & 0.9 & 2.2 & 1.6 & 1.0 & 0.4 & 1.1 & 0.6 & 0.7 & 0.3 & 0.6 & 0.6 & 4.5 & 2.6 & 0.2 & 0.6 & 2.2 & 2.0 & 0.5 & 0.6 & 2.1 & 1.7 & 0.4 & 0.4 & 1.4 & 89.6 & 1.0 & 73.9 \\
\hline Serviços (6) & 40.1 & 52.2 & 39.5 & 59.1 & 33.4 & 39.6 & 30.1 & 39.3 & 40.9 & 39.6 & 34.3 & 36.9 & 30.2 & \begin{tabular}{l|l}
31.8 \\
\end{tabular} & 24.2 & 22.7 & 12.0 & 10.7 & 30.3 & 30.7 & 10.9 & 12.8 & 25.7 & 29.0 & 29.3 & 33.7 & 33.7 & 42.2 \\
\hline Indústria (7) & 12.7 & 11.7 & 11.1 & 7.2 & 7.6 & 6.0 & 11.0 & \begin{tabular}{|l|}
10.4 \\
\end{tabular} & 8.7 & 8.0 & 12.3 & 13.1 & 11.9 & 15.0 & 9.9 & 13.2 & 10.3 & 10.6 & 12.3 & 11.4 & 11.3 & 11.8 & 9.2 & 8.1 & 10.7 & 14.7 & 10.5 & 25.8 \\
\hline Construção (8) & 2.0 & 2.1 & 3.6 & 3.7 & 3.8 & 2.8 & 2.7 & 2.8 & 2.6 & 2.1 & 2.0 & 2.7 & 1.2 & 1.1 & 3.0 & 1.2 & 1.5 & 2.8 & 1.5 & 1.9 & 0.7 & 0.4 & 0.3 & 0.3 & 2.1 & 53.3 & 2.0 & 53.0 \\
\hline \multicolumn{29}{|l|}{ Indís tria por } \\
\hline Recursos Naturais (9) & 4.2 & 5.0 & 4.3 & 2.1 & 3.4 & 1.7 & 3.9 & 2.1 & 4.5 & 3.3 & 3.1 & 3.2 & 10.3 & 6.9 & 6.9 & 3.5 & 13.4 & \begin{tabular}{c|}
9.5 \\
\end{tabular} & 10.5 & 11.1 & 13.9 & 11.2 & 18.0 & 15.5 & 8.0 & 62.6 & 6.3 & 72.3 \\
\hline Serviços (10) & 15.9 & 12.2 & 19.1 & 14.1 & 24.1 & 29.3 & 24.7 & 24.5 & 22.6 & 25.9 & 17.7 & 17.6 & 15.5 & 17.0 & 17.1 & 18.2 & 25.3 & 26.7 & 19.2 & 19.0 & 15.6 & 14.9 & 21.1 & 21.3 & 19.8 & 18.4 & 20.0 & 27.3 \\
\hline Indústria (11) & 12.8 & 6.7 & 9.6 & 3.6 & 11.9 & 10.6 & 15.3 & 10.6 & 7.8 & 9.3 & 13.1 & 13.5 & 7.6 & 8.4 & 21.0 & 27.7 & 19.7 & 14.3 & 13.4 & 11.4 & 23.6 & 25.3 & 11.7 & 9.2 & 14.0 & 36.5 & 12.6 & 56.8 \\
\hline Construção (12) & 0.3 & 0.2 & 0.2 & 0.1 & 0.8 & 0.5 & 0.7 & 0.6 & 0.3 & 0.3 & 0.4 & 0.5 & 0.1 & 0.1 & 0.1 & 0.1 & 0.3 & 1.6 & 0.2 & 0.1 & 0.1 & 0.0 & 0.2 & 0.2 & \begin{tabular}{l|l}
0.3 \\
\end{tabular} & 75.6 & 0.4 & 118.1 \\
\hline \multicolumn{29}{|l|}{ Construção por } \\
\hline Recursos Naturais (13) & 0.2 & 0.1 & 0.1 & 0.1 & 0.2 & 0.0 & 0.1 & 0.1 & 0.5 & 0.3 & 0.2 & 0.1 & 0.2 & 0.2 & 0.2 & 0.1 & 0.6 & 0.6 & 0.1 & 0.2 & 0.6 & 0.4 & 0.4 & 0.5 & \begin{tabular}{l|l}
0.3 \\
\end{tabular} & 62.1 & 0.2 & 80.1 \\
\hline Serviços (14) & 3.8 & 2.8 & 3.7 & 4.5 & 5.2 & 4.0 & 4.0 & 4.0 & 4.3 & 4.6 & 6.5 & 4.9 & 1.9 & 3.1 & 4.5 & 2.5 & 3.0 & 6.2 & 2.0 & 1.9 & 2.4 & 3.9 & 3.2 & 5.0 & 3.7 & 36.3 & 3.9 & 30.6 \\
\hline Indústria (15) & 4.0 & 2.6 & 3.0 & 1.9 & 5.6 & 3.0 & 4.5 & 3.3 & 3.1 & 3.1 & 7.7 & 4.9 & 5.0 & 5.0 & 10.0 & 8.1 & 5.9 & 10.2 & 4.8 & 4.3 & 9.7 & 11.2 & 3.8 & 4.4 & 5.6 & 42.5 & 5.2 & 58.7 \\
\hline Total & 100 & 100 & 100 & 100 & 100 & 100 & 100 & 100 & 100 & 100 & 100 & 100 & 100 & 100 & 100 & 100 & 100 & 100 & 100 & 100 & 100 & 100 & 100 & 100 & 100 & 0 & 100 & 0 \\
\hline Ind. Demanda Intermediária $(\mathrm{A}=9+10+11+12)$ & 33.3 & 24.1 & 33.2 & 19.9 & 40.2 & 42.1 & 44.5 & 37.7 & 35.3 & 38.8 & 34.4 & 34.8 & 33.5 & 32.4 & 45.1 & 49.5 & 58.7 & 52.0 & 43.2 & 41.6 & 53.2 & 51.5 & 50.9 & 46.2 & 42.1 & 20.7 & 39.2 & 26.1 \\
\hline variação (\%) & & -27.5 & & -40.1 & & 4.9 & & -15.3 & & 10.2 & & 1.3 & & -3.5 & & 9.8 & & -11.3 & & -3.9 & & -3.2 & & -9.3 & & & -6.9 & \\
\hline Ind Oferta Intermediária $\quad(B=3+7+11+15)$ & 30.6 & 22.4 & 24.7 & 13.0 & 26.1 & 20.1 & 31.6 & 24.9 & 21.1 & 21.6 & 33.9 & 32.7 & 28.4 & 31.3 & 42.9 & 50.5 & 38.4 & 36.8 & 32.9 & 30.4 & 50.4 & 52.2 & 27.2 & 23.9 & 32.4 & 25.5 & 30.0 & 39.6 \\
\hline variação (\%) & & -26.9 & & -47.4 & & -23.0 & & -21.2 & & 2.4 & & -3.6 & & 10.3 & & 17.8 & & -4.3 & & -7.7 & & 3.5 & & -12.1 & & & -7.3 & \\
\hline & & & & & & & & & & & & & & & & & & & & & & & & & & & & \\
\hline Serv. Demanda Intermediária $\quad(C=5+6+7+8)$ & 55.6 & 66.9 & 56.4 & 71.6 & 45.9 & 48.8 & 44.9 & 53.1 & 52.9 & 50.1 & 49.2 & 53.3 & 47.7 & 50.6 & 37.4 & 37.6 & 25.9 & 26.2 & 44.6 & 44.6 & 25.1 & 26.7 & 35.6 & 37.8 & 43.4 & 24.1 & 47.3 & 29.4 \\
\hline variação (\%) & & 20.3 & & 27.0 & & 6.3 & & 18.4 & & -5.4 & & 8.3 & & 6.1 & & 0.7 & & 1.0 & & 0.0 & & 6.5 & & 6.3 & & & 8.9 & \\
\hline Serv. Oferta Intermediária $\quad(\mathrm{D}=2+6+10+14)$ & 61.8 & 69.1 & 64.5 & 79.3 & 64.5 & 74.4 & 60.0 & 68.9 & 70.2 & 72.0 & 59.7 & 60.2 & 55.2 & 57.6 & 46.6 & 44.0 & 43.4 & 46.3 & 54.2 & 55.5 & 32.0 & 34.0 & 53.5 & 59.2 & 55.5 & 19.1 & 60.0 & 22.6 \\
\hline variação (\%) & & 11.8 & & 22.8 & & 15.3 & & 14.9 & & 2.4 & & 0.9 & & 4.4 & & -5.6 & & 6.6 & & 2.4 & & 6.2 & & 10.5 & & & 8.2 & \\
\hline
\end{tabular}

Tabela 1 - Participação das Atividades Econômicas nas Relações Intersetoriais de Países selecionados: 1995 e 2010 (\%)

Fonte: World Input-Output Database (WIOD). Elaborado pelos autores.

Notas: (1) A composição dos agregados é apresentada no anexo 3;

(2) CV: coeficiente de variação; 
Nessa perspectiva, além da hipótese dos três setores, para explicar o aumento da participação dos serviços no consumo intermediário é preciso combinar outros elementos que promoveram ou derivam da reestruturação industrial imposta pelas condições competitivas internacionais; em particular: (1) transferência (terceirização ou subcontratação) de certas atividades (alimentação, segurança, advocatícios, contábeis, saúde, etc) para os setores de serviços; (2) deslocamento de elos da cadeia de valor para o estrangeiro (offshoring) procurando as vantagens da especialização regional e ganhos de economias de escala pela concentração da produção; (3) como decorrência dos itens anteriores, as mudanças estruturais que geraram especialização produtivas e/ou reforçaram certas características nacionais em detrimento de outras.

A premissa principal desta pesquisa é que a intensificação das relações intersetoriais resultam em ganhos nas participações (oferta) dos serviços na economia. Ao mesmo tempo, defendemos que as interações entre os setores de serviços e da indústria estão sendo não apenas adensadas, mas, principalmente, criando complementariedades com características mais complexas e essenciais para o desenvolvimento econômico. No entanto, os resultados da Tabela 1 não parece apontar para um padrão internacional bem definido.

\section{Perfis das estruturas produtivas e as relações intersetoriais}

Os sistemas econômicos podem ser caracterizados pelas interdependências de comportamentos e informações e pelas formas interligadas e cada vez mais complexas dos fluxos de investimento, comércio, insumo, produto e inovação (SEMITIEL e NOGUERA, 2012 e, principalmente, SCHWEITZER et. al., 2009). Nessa perspectiva, o método de análise de redes é uma ferramenta que pode auxiliar na análise dessas interrelações/dependências. Entre as suas virtudes, o método possibilita a (1) seleção pelo valor (por exemplo, eliminando fluxos pouco relevantes) e a (2) elaboração de indicadores específicos que sumarizam as relações (3) visualização gráfica das interações.

A análise pelo método de redes fornece dois indicadores básicos: i) número de linhas ou de ligações da rede - elos entre nós (setores); e ii) densidade da rede ou relação entre elos reais e os possíveis; densidade $=m /(n(n-1))$, onde $n$ é o número de nós e $m$ é o número de linhas (GOYAL, 2007) ${ }^{6}$. Assim, a densidade da rede varia no intervalo [0, 1]; se a densidade é alta (próxima de 1), maior o número de ligações ou de relacionamentos e conexões entre os diferentes setores (SAVIOTTI, 2009). Neste estudo, densidade elevada

\footnotetext{
${ }^{6}$ Como este estudo trabalha como um número fixo de setores (nós), uma mudança na densidade decorre diretamente de variações nas relações intersetoriais (linhas).
} 
significa que a estrutura da economia é mais complexa, ou seja, os encadeamentos entre as atividades são mais diversificados ${ }^{7}$.

Para examinar as estruturas produtivas por meio do método de redes, optamos por limitar o número de relações intersetoriais: foram considerados apenas os fluxos intermediários superiores a US\$ 500 milhões (equivalente a US\$ 372 milhões de 1995 quando deflacionado pelo OECDindex), pois, exceto para o México, eles representam mais de $90 \%$ do total. Essa restrição permite manter os vínculos de fato relevantes e simplificar a análise dos resultados que o método oferece.

\begin{tabular}{|c|c|c|c|c|c|c|c|c|c|c|c|c|}
\hline \multirow[b]{3}{*}{ País } & \multirow{2}{*}{\multicolumn{3}{|c|}{ Densidade }} & \multicolumn{6}{|c|}{ Consumo Intermediário } & \multirow{2}{*}{\multicolumn{3}{|c|}{$\begin{array}{l}\text { Valor Adicionado } \\
\text { (US\$ bilhões) } \\
\end{array}$}} \\
\hline & & & & \multicolumn{3}{|c|}{ Total (US\$ bilhões) } & \multicolumn{3}{|c|}{ Nacional (US\$ bilhões) } & & & \\
\hline & 1995 & 2010 & $\begin{array}{c}\text { Variação } \\
(\%)\end{array}$ & $\begin{array}{l}1995 \\
(\mathrm{~A})\end{array}$ & $\begin{array}{l}2010 \\
\text { (B) }\end{array}$ & $\begin{array}{c}\text { Variação } \\
(\%)\end{array}$ & $\begin{array}{l}1995 \\
(\mathrm{C})\end{array}$ & $\begin{array}{c}2010 \\
\text { (D) }\end{array}$ & $\begin{array}{c}\text { Variação } \\
(\%)\end{array}$ & $\begin{array}{c}1995 \\
(\mathrm{E})\end{array}$ & $\begin{array}{l}2010 \\
(\mathrm{~F})\end{array}$ & $\begin{array}{c}\text { Variação } \\
\text { (\%) }\end{array}$ \\
\hline Alemanha & 441 & 0.410 & -7.1 & 2.553 & 2.911 & 14.0 & 2.076 & 2.132 & 2.7 & 3.061 & 2.982 & -2.6 \\
\hline EUA & 661 & 0.631 & -4.6 & 8.099 & 11.220 & 38.5 & 7.421 & 9.890 & 33.3 & 9.959 & 14.507 & 45.7 \\
\hline França & 335 & 0.349 & 4.3 & 1.731 & 2.233 & 29.0 & 1.393 & 1.738 & 24.7 & 1.879 & 2.333 & 24.1 \\
\hline Itália & 362 & 0.413 & 14.0 & 1.386 & 2.022 & 45.9 & 1.088 & 1.560 & 43.4 & 1.352 & 1.821 & 34.7 \\
\hline Japà & 33 & & .8 & 6.208 & 5.016 & -19.2 & 5.844 & 4.457 & -23.7 & 7.04 & 5.370 & -23.7 \\
\hline Reino Unido & 305 & 293 & -3.8 & 1.340 & 1.946 & 45.3 & 1.008 & 1.485 & 47.3 & 1.402 & 2.051 & 46.3 \\
\hline Total PD & 0.456 & 0.442 & -3.0 & 21.317 & 25.349 & 18.9 & 18.830 & 21.262 & 12.9 & 24.696 & 29.065 & 17.7 \\
\hline Brasil & & & .4 & 721 & 1.579 & & 570 & 1.334 & 134.1 & 904 & 1.803 & 99.4 \\
\hline China & 338 & 0.712 & 10.8 & 1.552 & 12.073 & 8.1 & 1.310 & 10.873 & 729.7 & 979 & 5.931 & 506.1 \\
\hline Coréia & 0.175 & 0.246 & 40.8 & 798 & 1.604 & 101.0 & 575 & 1.150 & 99.8 & 647 & 912 & 41.0 \\
\hline India & 140 & & 93.6 & \begin{tabular}{l|l}
478 \\
\end{tabular} & 1.548 & 223.6 & 350 & 1.240 & 253.9 & 469 & 1.562 & 232.7 \\
\hline México & 0.079 & 0.176 & 122.5 & 326 & 715 & 119.0 & 174 & 440 & 152.9 & 414 & 986 & 138.2 \\
\hline Rússia & 0.131 & 0.334 & 155.1 & 386 & 1.268 & 228.6 & 258 & 1.076 & 316.7 & 423 & 1.296 & 206.2 \\
\hline Total PeD & 0.185 & 0.353 & 90.4 & 4.262 & 18.787 & 340.8 & 3.238 & 16.112 & 397.5 & 3.837 & 12.491 & 225.6 \\
\hline Total & 0.321 & 0.398 & 24.0 & 25.579 & 44.136 & 72.5 & 22.068 & 37.375 & 69.4 & 28.533 & 41.556 & 45.6 \\
\hline
\end{tabular}

Tabela 2 - Características Gerais das Redes nos Países Selecionados

Fonte: World Input-Output Database (WIOD). Elaborado pelo autor a partir do e software Pajek . Notas:

(1) Países desenvolvidos (PD) e em desenvolvimento (PeD) contemplam apenas os países da amostra

(2) Total refere-se a média da (sub)amostra para os indicadores; demais colunas, (sub)total da amostra

(3) valores negritados realçam valores acima da média

(4) Valores deflacionados pelo OCDEindex.

Os indicadores da Tabela 2 sintetizam a heterogeneidade em termos de tamanho (valores), os perfis (mais ou menos densos) e as mudanças nas estruturas econômicas (variações no tempo) dos países da amostra, permitindo ordenar, classificar e comparar essas economias. Algumas observações interessantes podem ser extraídas dessa tabela.

Em primeiro lugar, há forte correlação direta entre densidade e magnitude da demanda intermediária (92\% e 91\% em 1995 e 2010, respectivamente), assim como entre esta última e o valor adicionado (90\% e 84\%) e entre densidade e valor adicionado (90\% e 75\%). Se a primeira correlação indica que o aumento (média de 72,5\%) do consumo

\footnotetext{
${ }^{7}$ Esta seção foi inspirada no estudo de HAUSMANN, Ricardo et al. (2014) que, diferente deste artigo, utilizou dados de comércio (produtos importados e exportados) para avaliara a estrutura produtiva dos países.
} 
intermediário agregado está, em geral, associado com o crescimento (24\%) das relações intersetoriais, as outras duas parecem apontar para o crescimento das diferenças nas estruturas econômicas nacionais - diferenças expressivas nas taxas nacionais de (de)crescimento de cada um dos agregados. Esses resultados parecem evidenciar tanto a importância da diversificação das relações intersetoriais (alta densidade) para o desenvolvimento econômico, como para estratégias nacionais distintas.

A Tabela 2 mostra ainda que apesar do expressivo aumento da densidade dos países em desenvolvimento (PeD) no período, as economias desenvolvidas (PD) ${ }^{8}$ se mantêm “estruturalmente mais complexas”. No entanto, as densidades dos PD cresceram negativamente (exceto Itália e França) e, por isso, a “defasagem” nas relações intersetoriais entre os dois blocos foi significativamente reduzida. Em particular, em 2010 a economia chinesa apresenta-se como "mais densa” - ou com “menos vazios" - do que as do EUA. Essa característica corrobora com o papel do país asiático como importante polo da manufatura mundial.

Esse perfil pode ser visualizado alternativamente no Anexo 1, que permite comparar China e EUA: (1) o diagrama da China tornou-se mais de denso ou "escuro" devido ao maior crescimento do número de relações intersetoriais; (2) representativas das magnitudes relativas, as "bolhas” maiores dos setores de serviços (demais setores) estão mais concentrados abaixo (acima) de uma hipotética bissetriz dos diagramas no caso dos EUA (China). Essa diferença estrutural, já anunciada nos comentários relativos à Tabela 1, significa que as demandas por insumos industriais e de serviços entre as duas economias têm proporções invertidas (52\% e 27\% para China e $24 \%$ e $67 \%$ para os EUA, respectivamente).

Por outro lado, a Tabela 2 mostra que o aumento (redução) nas densidades dos países em desenvolvimento (países em desenvolvidos) teve respaldo no expressivo crescimento (comparativamente baixo) do consumo intermediário. Ademais, o consumo intermediário total nos países desenvolvidos (em desenvolvimento) cresceu mais (menos) do que proporcionalmente a componente nacional desse consumo, ou seja, aumentou (diminui) a dependência de insumos importados. Em suma, as variações nos indicadores relativo aos dois blocos estão refletindo mudanças na divisão internacional do trabalho.

Adicionalmente, em geral, o valor adicionado dos países desenvolvidos cresceu a taxas inferiores a do consumo intermediário. Se considerarmos que o aumento do valor

\footnotetext{
${ }^{8}$ De acordo com a classificação da Unctad.
} 
adicionado dos PeD no período foi cerca de cinco vezes ao dos PD, a transferência de atividades econômicas dos países mais para os menos desenvolvidos foi amplamente favorável aos últimos. Nestas circunstâncias, os EUA podem ser o único caso bemsucedido de elevação da dependência de insumos estrangeiros e, ao mesmo tempo, aumento da relação entre valor adicionado e consumo intermediário (“margem de lucro”).

Como mencionado, o método de redes permite também a visualização gráfica tanto das redes formadas pelas relações intersetoriais, como das mudanças nessas relações. As estruturas econômicas dos países podem ser diferenciadas pelos valores (bolhas) que indicam a importância relativa do setor, pelo número de interações - maior número de linhas, mais “completa” é a rede ou complexa a economia - e pelas transformações que ocorrem ao longo do tempo. Por exemplo, entre Brasil e a Coréia há semelhanças nas participações relativas do setor de Coque, Petróleo Refinado; Combustível Nuclear; Substâncias e Produtos Químicos; Metalurgia e Produtos de Metal, que fazem parte de cadeias produtivas longas e, por isso, apresentam muitas interações -cerca de uma e meia dezena de linhas em 1995 para mais de trinta em 2010. Entretanto, há diferenças que marcam a especialização das duas economias: se as atividades coreanas são mais fortes em algumas indústrias (Máquinas e Equipamentos, Equipamentos Elétricos e Ópticos e Equipamentos de Transporte), as brasileiras concentram-se nas primárias (Recursos Naturais, Agricultura e Pesca e, Extrativa Mineral), indústria de bens de consumo (Alimentos, Bebidas e Tabaco) e terciário (intermediação financeira, comércio por varejo e Locação de Maquinas e Equipamentos e Outras Atividades de Negócios da Atividade de Serviços). Apesar de ser uma economia maior (dobro do PIB) e mais densa (50\%) ou “escura”, o perfil brasileiro está relacionado com o mercado interno (população cinco vezes maior) e exportador de bens primários - vide Anexo 2.

Em suma, o complexo industrial coreano é menos denso que o brasileiro (0,25 e 0,38 em 2010, respectivamente), mas os consumos intermediários são bastante similares. Além disso, o país asiático concentra as atividades nos setores industriais e, afora poucas exceções, as diferenças entre eles não são significativas (bolhas relativamente homogêneas), mas nitidamente superiores aos serviços - essas atividades são menores também em relação as dos EUA e China. Por outro lado, distintamente da China, as interações dos EUA estão concentradas na parte inferior da rede (Serviços, especialmente Locação de Maquinas e Equipamentos, Outras Atividades de Negócios e Intermediações financeiras) e a dimensão do setor industrial é menor. Assim, o método de redes permite 
avaliar as competências ou expertise nacionais, assim como as diferenças entre os tamanhos vis-à-vis a complexidade (rede) das duas economias.

\subsection{Relações intersetoriais}

A metodologia proposta nesta seção permite analisar e comparar as estruturas de diferentes economias a partir das relações intersetoriais. A vantagem do método proposto está em ressaltar as diferenças nas estruturas produtivas, seja pela indicação de diversificação/especialização em determinadas atividades (maior/menor número e/ou montantes), seja por meio das densidades (elos de demanda e oferta) dessas atividades. O indicador densidade total, que busca avaliar essas interações, é resultado da somatória das densidades “parciais”, ou seja, dos vínculos entre os setores $(k, j)-\mathrm{k}, \mathrm{j}=\mathrm{s}$ (serviços), i (indústria), r (recursos naturais) e c (construção). Considerando que este estudo prioriza as relações da indústria e serviços, os dois setores de recursos naturais são tratados como um único $^{9}$, ou seja, são desconsideradas as relações (densidades) internas - similar a construção. Assim, a densidade total pode ser denotada por:

Densidade total $=\frac{M i i}{n(n-1)}+\frac{M s s}{n(n-1)}+\frac{M s, i}{n(n-1)}+\frac{M s, r}{n(n-1)}+\frac{M r, i}{n(n-1)}+\frac{M c, i}{n(n-1)}+\frac{M c, i}{n(n-1)}+\frac{M r, c}{n(n-1)}$ n: número de setores;

$\mathrm{M}_{k, j}$ : Número de ligações entre os setores $\mathrm{k}$ e j, como definido acima;

$\mathrm{M}_{k, j} /[\mathrm{n}(\mathrm{n}-1)]$ - Densidade entre as relações intersetoriais das atividades k e j .

\footnotetext{
${ }^{9}$ A WIOD disponibiliza informações para 14 setores industriais, 17 de serviços e 2 de recursos naturais, além da construção, totalizando 34 atividades - vide anexo 3.
} 


\begin{tabular}{|c|c|c|c|c|c|c|c|c|c|c|c|c|c|c|c|c|c|c|c|c|c|c|}
\hline \multirow{3}{*}{ País } & \multicolumn{2}{|c|}{$\begin{array}{c}\text { Densidade } \\
(\mathrm{A}=\mathrm{B}+\mathrm{C}+\mathrm{D}+\mathrm{E}+\mathrm{F}+\mathrm{G}+\mathrm{H}+\mathrm{I})\end{array}$} & \multicolumn{2}{|c|}{ Interindustrial (B) } & \multicolumn{2}{|c|}{\begin{tabular}{|} 
Inters erviços \\
(C)
\end{tabular}} & \multicolumn{2}{|c|}{$\begin{array}{l}\text { Indústrias e } \\
\text { Serviços (D) }\end{array}$} & \multicolumn{2}{|c|}{$\begin{array}{c}\text { Recursos } \\
\text { Naturais e } \\
\text { Serviços (E) }\end{array}$} & \multicolumn{2}{|c|}{$\begin{array}{c}\text { Recursos } \\
\text { Naturais e } \\
\text { Indústrias (F) } \\
\end{array}$} & \multicolumn{2}{|c|}{\begin{tabular}{|c|} 
Construção e \\
Serviços (G)
\end{tabular}} & \multicolumn{2}{|c|}{$\begin{array}{l}\text { Construção e } \\
\text { Indústrias }(\mathrm{H})\end{array}$} & \multicolumn{2}{|c|}{\begin{tabular}{|c|} 
Recursos \\
Naturais e \\
Construção (I) \\
\end{tabular}} & \multicolumn{2}{|c|}{$\begin{array}{c}\text { Industria } \\
(\mathrm{J}=\mathrm{B}+\mathrm{D}+\mathrm{F}+\mathrm{H})\end{array}$} & \multicolumn{2}{|c|}{$\begin{array}{c}\text { Serviço } \\
(\mathrm{K}=\mathrm{C}+\mathrm{D}+\mathrm{E}+\mathrm{G})\end{array}$} \\
\hline & 1995 & 2010 & 1995 & 2010 & 1995 & 2010 & 1995 & 2010 & 1995 & 2010 & 1995 & 2010 & 1995 & 2010 & 1995 & 2010 & 1995 & 2010 & 1995 & 2010 & 1995 & 2010 \\
\hline & \multicolumn{18}{|c|}{ Densidade $[0,1]$} & \multicolumn{4}{|c|}{ Participação } \\
\hline Alemanha & 0.441 & 0.410 & 0.068 & 0.058 & 0.127 & 0.129 & 0.168 & 0.164 & $\mathbf{0 . 0 2 0}$ & 0.014 & \begin{tabular}{|l|}
0.015 \\
\end{tabular} & 0.007 & $\mathbf{0 . 0 2 5}$ & 0.023 & $\mathbf{0 . 0 1 7}$ & 0.013 & 0.002 & 0.001 & $\mathbf{0 . 2 6 7}$ & 0.242 & 0.340 & \begin{tabular}{|l|l|}
0.331 \\
\end{tabular} \\
\hline EUA & 0.661 & 0.631 & 0.103 & $\mathbf{0 . 0 8 6}$ & 0.187 & 0.185 & 0.266 & 0.251 & $\mathbf{0 . 0 2 9}$ & \begin{tabular}{|l|}
0.035 \\
\end{tabular} & \begin{tabular}{|l|l|}
0.029 \\
\end{tabular} & 0.026 & $\mathbf{0 . 0 2 2}$ & 0.024 & 0.021 & $\mathbf{0 . 0 1 9}$ & 0.003 & 0.004 & 0.421 & 0.382 & 0.504 & \begin{tabular}{|l|l|}
0.496 \\
\end{tabular} \\
\hline França & 0.335 & 0.349 & 0.031 & 0.042 & 0.129 & $\mathbf{0 . 1 3 0}$ & $\mathbf{0 . 1 2 1}$ & 0.131 & 0.014 & 0.007 & 0.011 & 0.011 & $\mathbf{0 . 0 1 9}$ & 0.018 & 0.008 & 0.009 & 0.002 & 0.002 & 0.171 & 0.193 & 0.283 & 0.286 \\
\hline Itália & 0.362 & 0.413 & 0.054 & 0.055 & 0.112 & 0.133 & $\mathbf{0 . 1 4 1}$ & 0.168 & 0.009 & 0.011 & 0.006 & 0.006 & \begin{tabular}{|l|}
0.024 \\
\end{tabular} & 0.024 & 0.014 & $\mathbf{0 . 0 1 5}$ & 0.001 & 0.001 & 0.216 & 0.244 & 0.286 & 0.335 \\
\hline Japão & 0.633 & 0.558 & 0.104 & $\mathbf{0 . 0 8 4}$ & 0.179 & 0.164 & 0.258 & 0.225 & $\mathbf{0 . 0 2 3}$ & 0.020 & \begin{tabular}{|l|}
0.019 \\
\end{tabular} & 0.018 & \begin{tabular}{|l|}
0.026 \\
\end{tabular} & 0.026 & 0.021 & $\mathbf{0 . 0 2 0}$ & 0.003 & 0.003 & 0.402 & 0.346 & 0.486 & 0.434 \\
\hline Reino Unido & 0.305 & 0.293 & 0.038 & 0.013 & 0.124 & 0.143 & 0.101 & 0.093 & 0.012 & 0.013 & 0.005 & 0.004 & \begin{tabular}{|l|}
0.017 \\
\end{tabular} & $\mathbf{0 . 0 2 0}$ & 0.007 & 0.006 & 0.001 & 0.001 & 0.152 & 0.116 & 0.253 & 0.269 \\
\hline Brasil & 0.250 & 0.378 & 0.034 & 0.051 & 0.080 & 0.122 & 0.091 & 0.122 & 0.012 & 0.020 & 0.012 & 0.020 & 0.012 & 0.014 & 0.007 & $\mathbf{0 . 0 2 7}$ & 0.001 & 0.003 & 0.144 & 0.219 & 0.195 & 0.278 \\
\hline China & 0.338 & 0.712 & $\mathbf{0 . 0 8 5}$ & 0.143 & 0.059 & 0.152 & 0.120 & 0.299 & $\mathbf{0 . 0 1 9}$ & 0.040 & \begin{tabular}{|l|}
0.032 \\
\end{tabular} & 0.042 & 0.014 & 0.023 & 0.009 & 0.008 & 0.000 & 0.004 & 0.246 & 0.492 & 0.212 & 0.514 \\
\hline Coréia & 0.175 & 0.246 & 0.037 & 0.054 & 0.046 & 0.066 & 0.063 & 0.097 & 0.002 & \begin{tabular}{|l|}
0.004 \\
\end{tabular} & 0.007 & 0.006 & 0.009 & 0.010 & 0.009 & 0.008 & 0.001 & 0.000 & 0.117 & 0.166 & 0.120 & 0.177 \\
\hline Índia & 0.131 & 0.334 & 0.010 & 0.037 & 0.053 & 0.114 & 0.032 & 0.115 & 0.014 & 0.022 & 0.012 & 0.018 & 0.005 & 0.019 & 0.004 & 0.008 & 0.000 & 0.002 & 0.058 & 0.177 & 0.105 & 0.270 \\
\hline México & 0.079 & 0.176 & 0.010 & 0.021 & 0.024 & 0.063 & 0.024 & 0.054 & 0.005 & 0.012 & 0.009 & 0.012 & 0.004 & 0.006 & 0.002 & 0.006 & 0.001 & 0.001 & 0.045 & 0.094 & 0.058 & 0.136 \\
\hline Rússia & 0.140 & 0.271 & .023 & 0.058 & 0.022 & 0.048 & 0.061 & 0.100 & 0.007 & 0.010 & 0.012 & 0.018 & 0.008 & 0.018 & 0.004 & $\mathbf{0 . 0 1 7}$ & 0.003 & 0.003 & 0.100 & .193 & 0.098 & 0.176 \\
\hline \multirow[t]{2}{*}{ Média } & 0.337 & 0.409 & 0.052 & 0.059 & 0.102 & 0.127 & 0.126 & 0.156 & 0.014 & 0.018 & 0.014 & 0.015 & 0.016 & 0.019 & 0.011 & 0.013 & 0.001 & 0.002 & 0.203 & 0.243 & 0.258 & 0.321 \\
\hline & \multicolumn{18}{|c|}{ Participação Relativa (\%) } & \multicolumn{4}{|c|}{ Participação } \\
\hline Alema & 100 & 100 & 15.4 & 14.1 & 28.9 & 31.5 & 38.0 & 40.0 & 4.4 & 3.5 & 3.4 & 1.7 & 5.7 & 5.7 & 3.8 & 3.3 & 0.4 & 0.2 & 60.6 & 59.1 & 77.0 & 80.7 \\
\hline EUA & 100 & 100 & 15.6 & 13.7 & 28.3 & \begin{tabular}{|r|}
29.4 \\
\end{tabular} & 40.3 & 39.8 & 4.3 & 5.5 & 4.4 & 4.1 & 3.4 & 3.8 & 3.2 & 3.0 & 0.4 & 0.7 & 63.6 & 60.6 & 76.3 & 78.5 \\
\hline França & 100 & 100 & 9.3 & 12.0 & 38.6 & \begin{tabular}{|l|}
37.2 \\
\end{tabular} & 36.2 & 37.5 & 4.3 & 2.0 & 3.2 & 3.1 & 5.6 & 5.1 & 2.4 & 2.6 & 0.5 & 0.5 & 51.1 & 55.1 & 84.6 & 81.9 \\
\hline Itália & 100 & 100 & 15.0 & 13.4 & 31.0 & 32.2 & 38.9 & 40.6 & 2.5 & 2.6 & 1.7 & 1.5 & 6.7 & 5.8 & 3.9 & 3.7 & 0.2 & 0.2 & 59.6 & 59.2 & 79.1 & 81.2 \\
\hline Japão & 100 & 100 & 16.5 & 15.0 & 28.3 & 29.4 & 40.7 & 40.3 & 3.7 & 3.5 & 3.0 & 3.2 & 4.1 & 4.6 & 3.4 & 3.5 & 0.4 & 0.5 & 63.5 & 62.0 & 76.8 & 77.8 \\
\hline Reino Unido & 100 & 100 & 12.6 & 4.6 & 40.6 & 48.6 & 33.0 & 31.6 & 3.8 & 4.6 & 1.8 & 1.2 & 5.6 & 7.0 & 2.3 & 2.1 & 0.3 & 0.3 & 49.7 & 39.5 & 83.0 & 91.8 \\
\hline Média PD & 100 & 100 & 14.1 & 12.1 & 32.6 & 34.7 & 37.9 & 38.3 & 3.8 & 3.6 & 2.9 & 2.5 & 5.2 & 5.3 & 3.2 & 3.0 & 0.4 & 0.4 & 58.0 & 55.9 & 79.4 & 82.0 \\
\hline Brasil & 100 & 100 & 13.6 & 13.4 & 32.1 & 32.3 & 36.4 & 32.3 & 5.0 & 5.2 & 5.0 & 5.2 & 4.6 & 3.8 & 2.9 & 7.1 & 0.4 & 0.7 & 57.9 & 58.0 & 78.2 & 73.6 \\
\hline China & 100 & 100 & 25.1 & 20.2 & 17.4 & 21.4 & 35.6 & 41.9 & 5.5 & 5.6 & 9.5 & 5.9 & 4.2 & 3.3 & 2.6 & 1.1 & 0.0 & 0.6 & 72.8 & 69.1 & 62.8 & 72.2 \\
\hline Coréia & 100 & 100 & 21.4 & 22.1 & 26.5 & 26.8 & 36.2 & 39.5 & 1.0 & 1.8 & 4.1 & 2.5 & 5.1 & 4.0 & 5.1 & 3.3 & 0.5 & 0.0 & 66.8 & 67.4 & 68.9 & 72.1 \\
\hline Rússia & 100 & 100 & 7.5 & 10.9 & 40.8 & 34.1 & 24.5 & 34.4 & 10.9 & 6.7 & 8.8 & 5.3 & 4.1 & 5.6 & 3.4 & 2.4 & 0.0 & 0.5 & 44.2 & 53.1 & 80.3 & 80.8 \\
\hline México & 100 & 100 & 12.4 & 12.1 & 30.3 & 35.9 & 30.3 & 30.8 & 6.7 & 7.1 & 11.2 & 6.6 & 5.6 & 3.5 & 2.2 & 3.5 & 1.1 & 0.5 & 56.2 & 53.0 & 73.0 & 77.3 \\
\hline Índia & 100 & 100 & 16.6 & 21.4 & 15.9 & 17.8 & 43.3 & 36.8 & 5.1 & 3.6 & 8.3 & 6.6 & 5.7 & 6.6 & 3.2 & 6.3 & 1.9 & 1.0 & 71.3 & 71.1 & 70.1 & 64.8 \\
\hline Média PeD & 100 & 100 & 16.1 & 16.7 & 27.2 & 28.0 & 34.4 & 36.0 & 5.7 & 5.0 & 7.8 & 5.3 & 4.9 & 4.5 & 3.2 & 3.9 & 0.7 & 0.6 & 61.5 & 61.9 & 72.2 & 73.5 \\
\hline Média & 100 & 100 & 15.1 & 14.4 & 29.9 & 31.4 & 36.1 & 37.1 & 4.8 & 4.3 & 5.4 & 3.9 & 5.0 & 4.9 & 3.2 & 3.5 & 0.5 & 0.5 & 59.8 & 58.9 & 75.8 & 77.7 \\
\hline \multicolumn{3}{|c|}{ Coeficiente Variação PD $(<\mathbf{2 5 \%})$} & 19.0 & 31.7 & 17.0 & 21.3 & 7.6 & 9.0 & 19.2 & 35.1 & 35.8 & 46.3 & 23.2 & 20.4 & 21.6 & 19.6 & 26.5 & 47.9 & - & - & - & - \\
\hline \multicolumn{3}{|c|}{ Coeficiente Variação PeD $(<\mathbf{2 5 \%})$} & 39.7 & 30.3 & 34.6 & 26.1 & 18.5 & 11.9 & 55.8 & 39.6 & 35.1 & 28.0 & 14.3 & 29.8 & 30.8 & 57.9 & 114.3 & 57.9 & - & - & - & - \\
\hline \multicolumn{3}{|c|}{ Coeficiente Variação $(<\mathbf{2 5 \%})$} & 31.7 & 34.0 & 26.4 & 25.0 & 14.0 & 10.5 & 50.6 & 40.4 & 60.3 & 50.3 & 18.8 & 25.5 & 25.5 & 47.8 & 101.5 & 55.4 & - & - & - & - \\
\hline
\end{tabular}

Tabela 3 - Densidade dos Países Selecionados por Atividade Econômica (1995 e 2010)

Fonte Matriz Insumo-produto de 2010 (WIOD). Elaboração pelo autor a partir do software Pajek.

Notas:

(1) Países desenvolvidos (PD) e em desenvolvimento (PeD) contemplam apenas os países da amostra 
Os indicadores da Tabela 3 possibilitam avaliações em quatro dimensões: i) importância das relações entre as diferentes atividades - destacaremos a interação entre indústria e serviços; ii) mudanças na estrutura nacional ocorridas entre os dois anos selecionados; iii) diferenças estruturais entre os países em desenvolvimento e os subdesenvolvidos, por meio do confronto desses dois grupos, e; iv) comparações nacionais - aqui nos limitamos aos paralelos já adotados: China e EUA; Brasil e Coréia.

A Tabela 3 reforça e avança na análise feita na seção anterior sobre a participação da indústria na economia: além da diminuição da densidade industrial não ter sido um caso generalizado, a perda de participação dessas relações foi pouco significativa no período (cerca de 60\% e 59\%, respectivamente) - vide coluna J. A redução nessa proporção decorreu exclusivamente de mudanças nos PDs (EUA, especialmente Japão e Reino Unido), pois a ela permaneceu praticamente constante nos PEDs (cerca de 61\%). Observese que o último bloco de países apresentou forte incremento na densidade.

Em outras palavras, mesmos que as transações da indústria com as demais atividades tenham diminuído em termos relativos nos países desenvolvidos (-2\%, assim como nas relações interindustriais - vide coluna J e B), isso não parece representar uma ruptura nas relações dessa com as outras atividades. Ademais, como também houve pequeno aumento na participação das atividades interindustriais, no caso dos países em desenvolvimento o deslocamento de elos industriais das cadeias de valor parece ter compensado um possível processo de transferências de atividades da indústria para serviços - vide coluna C. Em suma, se os PeD adensaram as relações dentro e entre as atividades industriais e de serviços, a "reestruturação" nos países desenvolvidos foi bem mais assimétrica ou heterogênea. Assim, se para o primeiro bloco de países o processo de expansão das economias passou pelo aumento das densidades ou complexidades das relações econômicas, para o segundo há um padrão definido.

A maioria das relações da indústria com a estrutura produtiva está vinculada aos setores de serviços (cerca 37\% em 2010; coluna D), com maior intensidade nos PDs do que nos países em desenvolvimentos (38\% e 36\%, respectivamente). Ressalte-se que os coeficientes de variação (CV) da amostra são relativamente heterogêneos (em torno de 30\%) para as relações interindustriais (indicando diferenças estruturais), mas são bastante homogêneos para as relações interserviços nos dois blocos de países (em torno de 10\%, respectivamente). Em suma, as mudanças nas relações serviços são bem mais "padronizadas” do que as ocorridas nas industriais. 
Os setores industriais e de serviços mantêm fortes vínculos, seja pela especialização desses últimos decorrente da terceirização de funções dos primeiros, seja pela criação de novos serviços prestados a empresas a partir de avanços tecnológicos. No conjunto, as atividades industriais são as mais relevantes para relações intermediárias dos serviços, indiferente do bloco de países, mas especialmente para os países desenvolvidos cujo terciário é mais denso. Os serviços perderiam cerca de metade da sua relevância sem a indústria, inclusive superior aos próprios vínculo internos das atividades de serviços colunas D e K.

Além das densidades interserviços serem superiores às demais (exceto para a Índia - coluna C), a participação do conjunto das atividades de serviços nas economias nacionais aumenta durante o período em estudo, passando de 76\% para 78\% (coluna K), respectivamente. Ademais, nos países desenvolvidos essas relações são mais intensas (79\% e 82\%, em 1995 e 2010, respectivamente) do que nos países em desenvolvimentos (72\% e $74 \%)$.

Observemos um caso especial: em 2010, a participação do conjunto de vínculos das atividades de serviços no total do Reino Unido alcança 92\% (maior da amostra). A explicação para esse percentual elevadíssimo está na densidade das atividades de serviços: ela é significativamente maior do que qualquer outra (colunas C e K). Adicionalmente, a densidade total (coluna A) da região não só foi reduzida no período (-4\%), mas tornou-se uma das menores da amostra. Este parece ser um caso distintivo: redução (-24\%) dos elos da indústria - não compensada pelo crescimento (6\%) dos serviços - e convergência para uma economia amplamente baseada nos serviços.

Os indicadores da Tabela 3 permitem também complementar a discussão anterior sobre as mudanças e heterogeneidades nas estruturas produtivas. É possível, por exemplo, agrupar os países segundo a variação nas densidades. O primeiro grupo caracteriza-se pelos países em que houve redução da densidade (eliminação de elos intersetoriais): o padrão dominante desse conjunto é a diminuição dos elos interindustriais (Alemanha, EUA, Japão e Reino Unido; coluna B), mas, em alguns casos (EUA, Japão; coluna C), há também perda de densidade nos serviços. O segundo grupo é de países (todos os demais) que expandiram as relações setoriais (aumento da densidade) através do crescimento tanto das densidades interindustriais, quanto de serviços (principalmente). Nesse último grupo, se os elos da indústria com as demais atividades evoluíram a taxas - França (12\%), Itália (13\%), Brasil (52\%), China (100\%), Coréia (42\%), Rússia (93\%), México (110\%) ou Índia (200\%) - significativas, os vínculos relativos aos serviços acompanharam - 1\%, 17\%, 42\%, 
142\%, 47\%, 79\%, 135\% e 157\%, respectivamente. Ressalte-se que neste conjunto há economias em diferentes graus de complexidade, desde aquelas com grande parte dos elos possíveis já estruturados (China, 0,71), outras em nível intermediário (Itália, 0,36, Brasil, 0,34; Índia, 0,33) e algumas menos densas (Coréia, 0,25; Rússia, 0,23 e México 0,18)

Alguns casos podem ser tomados como exemplares. Entre 1995 e 2010, houve um crescimento extraordinário da densidade chinesa (de 0,34 para 0,71; coluna A) devido ao aumento dos elos das atividades relacionadas aos serviços (de 0,21 para 0,51; coluna K) e industriais (de 0,25 para 0,49; coluna J). Se, por um lado, crescimento mais que proporcional dos serviços representou perda de participação relativa dos setores industriais (de 73\% para 69\%), por outro lado, promoveu o aumento da densidade das relações entre serviços e indústria (de 0.12 para 0,30). Assim, a crescente participação dos serviços na estrutura economia da China está intimamente ligada com seus vínculos com a indústria (coluna D).

O exemplo dos EUA é distinto do chinês, mesmo sendo similares em um ponto: diminuição da participação dos setores industriais em razão do aumento da quota dos setores de serviços. No período, a densidade dos EUA diminui (-4\%) em razão da queda da densidade do setor industrial (-9\%) e dos serviços (-2\%). Em síntese, como já mencionado, a redução acentuada da densidade da indústria parece promover a queda da densidade dos serviços. Além disso, se a economia do Reino Unido "reforçou" os elos interserviços em detrimento dos industriais, os EUA parecem ter transferido parte de ambas as atividades para o estrangeiro. A China, por sua vez, absorveu as atividades "preteridas”.

A nossa segunda comparação, entre Coréia e Brasil, procura complementar as características observadas na seção 3. Apesar do forte crescimento no período, a densidade da Coréia continua inferior à do Brasil (0,25 e 0,34 em 2010, respectivamente). Esses índices decorrem das diferenças nos tamanhos (PIB) e complexidade das economias (há forte diferencial favorável ao Brasil, por exemplo, em termos de recursos naturais), que estabelecem inúmeros elos econômicos que se refletem nas densidades. Ademais, a participação dos elos da indústria com a economia coreana e brasileira mantiveram-se praticamente constante (cerca de $67 \%$ e 58\%, respectivamente). No entanto, se esse percentual do país asiático é superior ao dos demais países da amostra, (exceto China e Índia), o brasileiro se mantém abaixo da média dos PEDs.

A Coréia acompanhou a média mundial no que tange a densidade das atividades de serviços, mas a elevação dessa participação também esteve vinculada com a elevação das relações entre indústria e serviços. O Brasil, porém, apresentou comportamento diverso, 
com queda significativa na participação dos serviços e das suas interações com a indústria, mas ampliou os elos do secundário com a construção. Essas considerações podem ser indícios não só de mudanças no papel da indústria da economia brasileira, mas também de um redirecionamento do setor de serviços para a demanda final, com perda de encadeamentos importantes na estrutura produtiva.

\section{Considerações Finais}

Este estudo examinou as mudanças recentes nas interações intersetoriais de diferentes países a partir da hipótese de que o aumento da participação das atividades de serviços pode promover um redimensionamento da indústria ao longo do processo de desenvolvimento econômico. Todavia, essas transformações não implicam necessariamente em diminuição do papel e importância das atividades secundárias nesse processo. Nessa perspectiva, além dos tradicionais coeficientes de consumo intermediário, propomos novos indicadores obtidos pela aplicação do método de redes sobre esses coeficientes. Os resultados permitem quantificar os vínculos entre as atividades econômicas em diferentes países e ressaltar o valor e significado das relações dos setores de serviços e industriais na estrutura produtiva. Em termos da metodologia, a proposta mostra virtudes interessantes, seja pelos resultados, seja pelo potencial em termos de aperfeiçoamentos possíveis e instrumento auxiliar em estudos de distintas perspectivas. Os resultados alcançados indicam que as relações entre indústria e serviços estão sendo intensificadas à medida que cresce a participação das atividades de serviços na economia. Ademais, nos países em que as relações intermediárias entre serviços e indústria se expandiram, a economia tornou-se mais complexa, ou seja, houve um adensamento dos vínculos intersetoriais. Nessas circunstâncias, a taxa de crescimento do valor adicionado e foi, em geral, bastante superior a das demais nações.

\section{Bibliografia}

ARBACHE, J. Por que serviços? in "Indústria e Desenvolvimento Produtivo no Brasil", Orgs. N. Barbosa, N. Marconini. M.C. Pinheiro e L. Carvalho, São Paulo: Elsevier e FGV, 2015.

BAUMOL, W. J. The Cost Disease: Why Computers Get Cheaper and Health Care Doesn't. Yale university press. 2012.

BAUMOL, W. J. 'Paradox of the Services: Exploding Costs, Persistent Demand'. In: Ten Raa, T./ Schettkat, R. (eds.) The Growth of Service Industries: The Paradox of Exploding Costs and Persistent Demand. Cheltenham: Edward Elgar. pp. 3 - 28. 2001. 
BAUMOL, W. J. 'Macroeconomics of Unbalanced Growth: the Anatomy of Urban Crisis'. In: American Economic Review, Vol. 57, pp. 415 - 426.1967.

BAUMOL, W.J.; BOWEN, W.G. Performing Arts: The Economic Dilemma. New York: Twentieth Century Fund.1966.

BAUMOL, W.J., BLACKMAN, S.A.B.; WOLFF, E.N. Unbalanced growth revisited: asymptotic stagnancy and new evidence. American Economic Review 75: 806- 817.1985.

BRESSER-PEREIRA, L. C.; MARCONI, N. Existe Doença Holandesa no Brasil? In: Bresser-Pereira, L. C. (org.), Doença holandesa e indústria (coletânea). Editora FGV. Rio de Janeiro. 2010.

CANO, W. A desindustrialização no Brasil. Texto para discussão n 200, IE/UNICAMP. Janeiro. Campinas. 2012.

CERINA, F., ZHU, Z., CHESSA, A., \& RICCABONI, M. World input-output network. arXiv preprint arXiv:1407.0225. 2014.

CLARK, C. (1940, revised and reprinted in 1951) The Conditions of Economic Progress.

London: MacMillan \& Co. Ltd. 1951

FEIJÓ, C. A. E CARVALHO, P. G. M. Desindustrialização e os Dilemas do Crescimento Econômico Recente. IEDI, mimeo. São Paulo: IEDI. 2007.

FISHER, A.G.B. The Clash of Progress and Security. London: MacMillan \& Co. Ltd. 1935.

FUCHS, V.R. The Service Economy. New York and London: Colombia University Press. 1968

GOYAL, S. Connections: An Introduction to the Economics of Networks, Princeton University Press, Princeton and Oxford. 2007.

HAUSMANN, Ricardo et al. The atlas of economic complexity: Mapping paths to prosperity. Mit Press, 2014.

HIRSCHMAN, A. O. Desenvolvimento por efeitos em cadeia: uma abordagem generalizada. Economia e movimentos sociais na américa latina. São Paulo: Brasiliense, 31-79. 1985.

HIRSCHMAN, A. The Strategy of Economic Development. Yale University Press. 1958.

KALDOR, N. Problems of Industrialization in Underdeveloped Countries. Ithaca: Cornell University Press. 1967.

KATOUZIAN, M.A.'The Development of the Service Sector: A New Approach'. In:

Oxford Economic Papers, pp. 362 - 382. 1970.

KONGSAMUT, P., REBELO, S. E; XIE, D. Beyond balanced growth. Reviewof Economic Studies 68: 869-882. 2001.

KUZNETS, S. Quantitative aspects of the economic growth of nations: II. Industrial distribution of national product and labour force. Economic Development and Cultural Change 5 (supplement): 3-111. 1957.

KUZNETS, S. Modern Economic Growth: Rate, Structure, and Spread. New Haven, CT: Yale University Press. 1966.

NASSIF, A. Há Evidência de Desindustrialização no Brasil? Revista de Economia Política. v. 28, n ${ }^{\circ}$ 1, jan/mar. p. 72-96. 2008. 
OCDE (2013) Interconnected Economies: Benefiting from global value chains. New York and Geneva., United Nations. 2013.

PALMA, J. G. Quatro fontes de industrialização e um novo conceito de doença holandesa. Texto apresentado na conferência sobre industrialização e desindustrialização, FIESP/IEDI. 2005.

PREBISCH, R. O desenvolvimento da América Latina e seus principais problemas. Revista Brasileira de Economia. Ano 3, n 3, Setembro. Rio de Janeiro: Fundação Getúlio Vargas. 1949.

ROWTHORN, R.; RAMASWAMY, R. Growth, Trade and Deindustrialization. International Monetary Fund Staff Papers, Vol. 46, N.1. 1999

SAVIOTTI, P.P. Chapter 2 - Knowledge Networks: Structure and Dynamics. In A. Pyka, A. Scharnhorst (eds.), Innovation Networks, Understanding Complex Systems, DOI 10.1007/978-3-540-92267-4 2, C Springer-Verlag Berlin Heidelberg. 2009.

SCHETTKAT, R.; YOCARINI, L. The shift to services employment: A review of the literature. Structural Change and Economic Dynamics 17.2 (2006): 127-147. 2006.

SCHWEITZER, F., FAGIOLO, G., SORNETTE D., VEGA-REDONDO, F. E WHITE, D. Economic Networks: What Do We Know And What Do We Need To Know?. Advances in Complex Systems: A Multidisciplinary Journal. Volume 12, Issue 04n05, August \& October 2009

SEMITIEL-GARCÍA, M.; NOGUERA-MÉNDEZ, P. The structure of inter-industry systems and the diffusion of innovations: The case of Spain. Technological Forecasting \& Social Change 79 (2012) 1548-1567. 2012.

SINGH, A. Manufacturing and de-industrialization. In: Eatwell, J.; Milgate, M.; Newman, P. (org.). The New Palgrave: A Dictionary of Economics. Vol. 3. London: Macmillan. 1987.

SUMMERS, R. Services in the International Economy. In: Inman, R.P (ed.) Managing the Service Economy. Cambridge: CUP. pp. 27 - 48. 1985.

THIRLWALL, A. P. A Natureza do Crescimento Econômico: um referencial alternativo para compreender o desempenho das nações. Editora do IPEA. Brasília. 2005.

TREGENNA, F. Characterising deindustrialisation: An analysis of changes in manufacturing employment and output internationally. Cambridge Journal of Economics, 33, 433-466. 2008.

WIOD, World Input-Output Database, disponível em: http://www.wiod.org/new_site/home.htm. 2014 

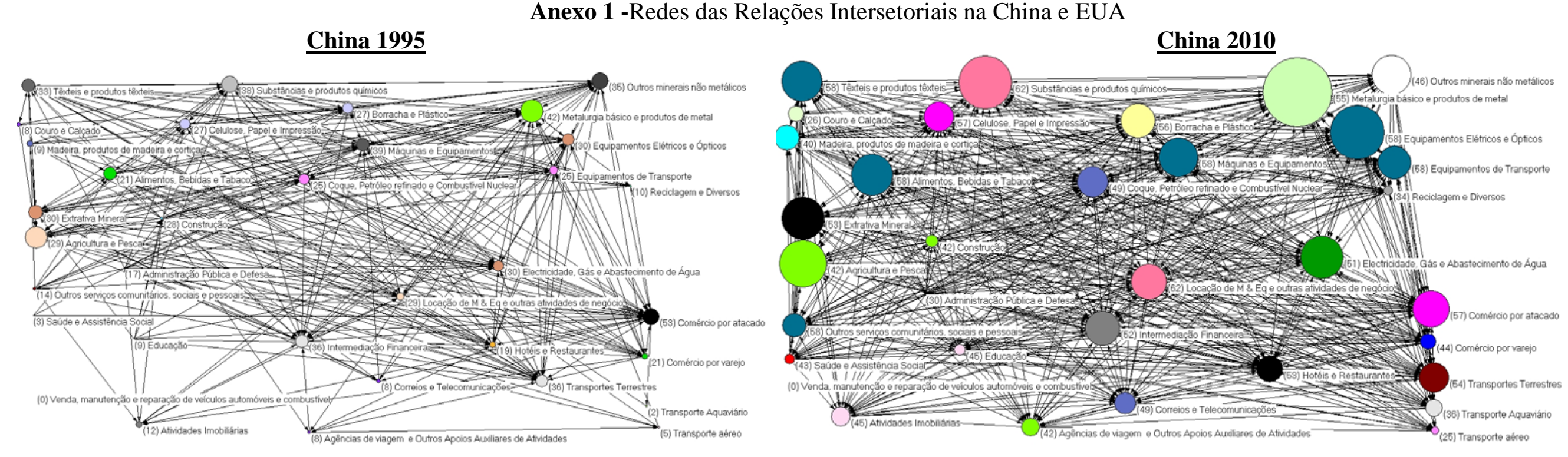

EUA 1995
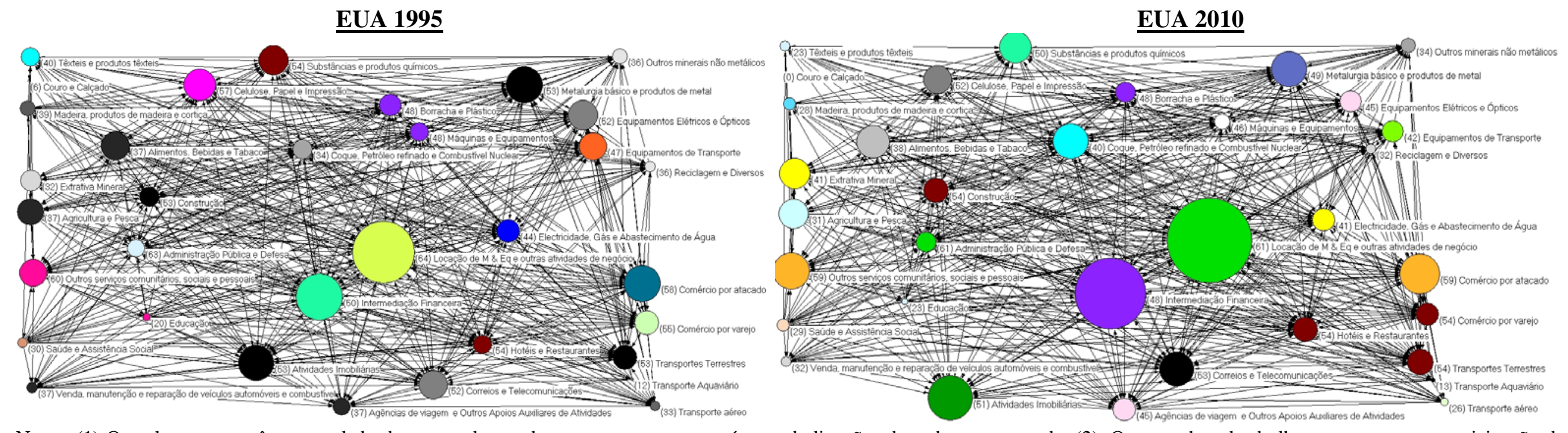

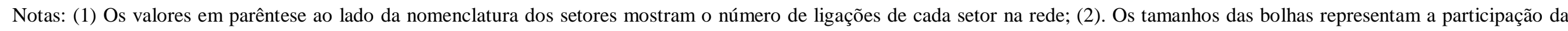
oferta dos setores na economia.

Fonte: Elaboração própria a partir de dados da Matriz Insumo-produto de 2010 (WIOD) e software Pajek. 

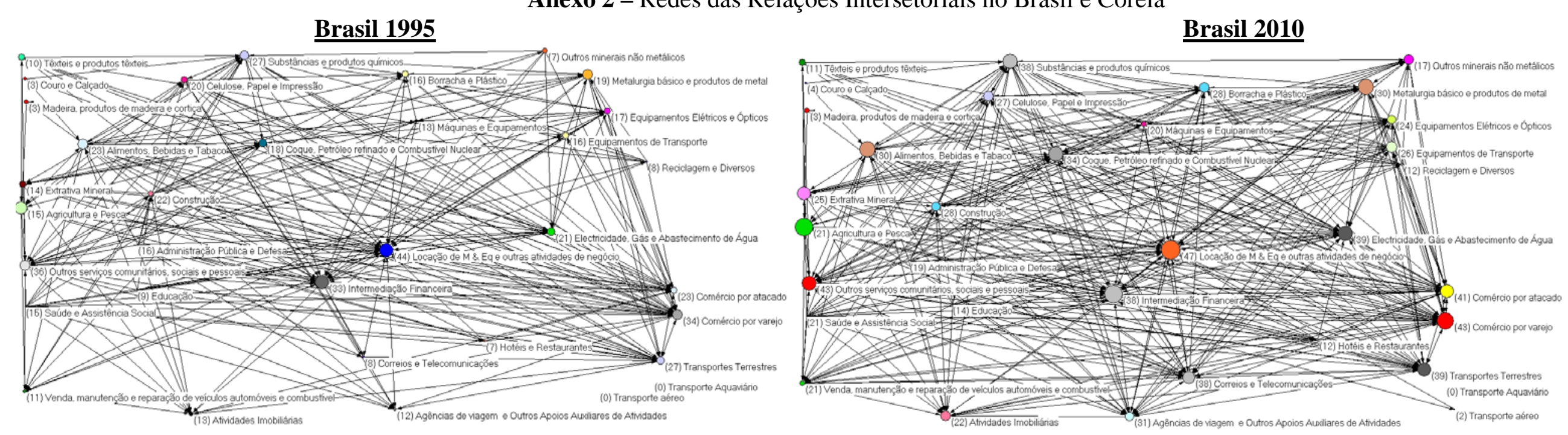

\section{Coréia 1995}
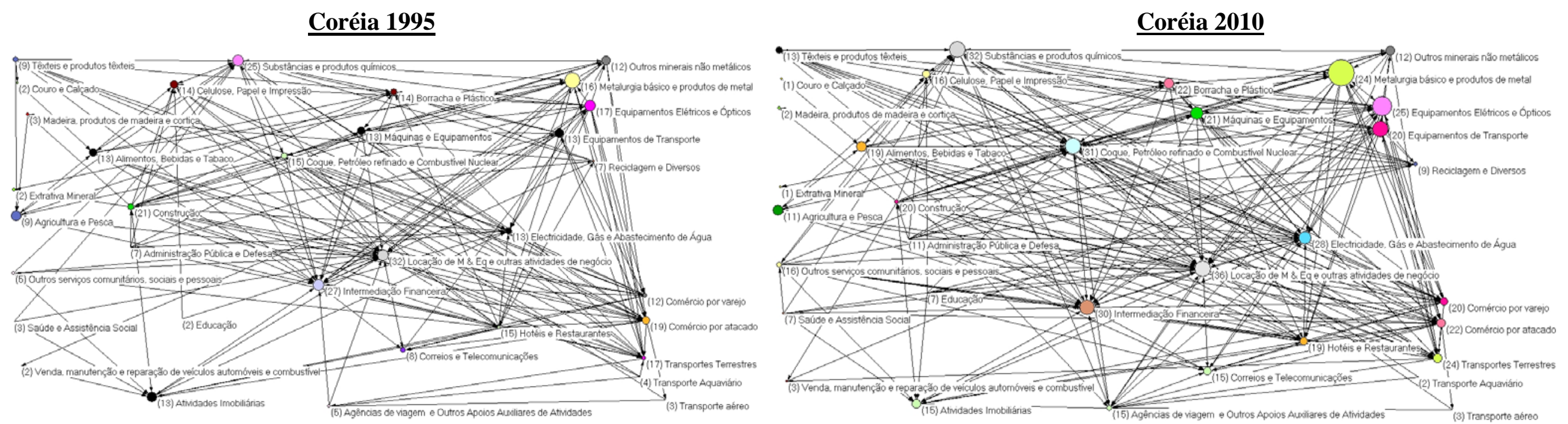

Notas: (1) Os valores em parêntese ao lado da nomenclatura dos setores mostram o número de ligações de cada setor na rede; (2). O tamanho da bolha representa a participação da oferta dos setores na economia.

Fonte: Elaboração própria a partir de dados da Matriz Insumo-produto de 2010 (WIOD) e software Pajek. 
Anexo 3 - Agregados Setoriais

\begin{tabular}{|c|c|c|}
\hline \multirow{2}{*}{ Recursos Naturais } & AtB & Agriculture, Hunting, Forestry and Fishing \\
\hline & $\mathrm{C}$ & Mining and Quarrying \\
\hline \multirow{14}{*}{ Indústria } & $15 \mathrm{t} 16$ & Food, Beverages and Tobacco \\
\hline & $17 \mathrm{t} 18$ & Textiles and Textile Products \\
\hline & 19 & Leather, Leather and Footwear \\
\hline & 20 & Wood and Products of Wood and Cork \\
\hline & $21 \mathrm{t} 22$ & Pulp, Paper, Paper, Printing and Publishing \\
\hline & 23 & Coke, Refined Petroleum and Nuclear Fuel \\
\hline & 24 & Chemicals and Chemical Products \\
\hline & 25 & Rubber and Plastics \\
\hline & 26 & Other Non-Metallic Mineral \\
\hline & $27 \mathrm{t} 28$ & Basic Metals and Fabricated Metal \\
\hline & 29 & Machinery, Nec \\
\hline & $30 \mathrm{t} 33$ & Electrical and Optical Equipment \\
\hline & $34 \mathrm{t} 35$ & Transport Equipment \\
\hline & $36 \mathrm{t} 37$ & Manufacturing, Nec; Recycling \\
\hline Construção & $\mathrm{F}$ & Construction \\
\hline \multirow{17}{*}{ Serviços } & $\mathrm{E}$ & Electricity, Gas and Water Supply \\
\hline & 50 & Sale, Maintenance and Repair of Motor Vehicles and Motorcycles; Retail Sale of Fuel \\
\hline & 51 & Wholesale Trade and Commission Trade, Except of Motor Vehicles and Motorcycles \\
\hline & 52 & Retail Trade, Except of Motor Vehicles and Motorcycles; Repair of Household Goods \\
\hline & $\mathrm{H}$ & Hotels and Restaurants \\
\hline & 60 & Inland Transport \\
\hline & 61 & Water Transport \\
\hline & 62 & Air Transport \\
\hline & 63 & Other Supporting and Auxiliary Transport Activities; Activities of Travel Agencies \\
\hline & 64 & Post and Telecommunications \\
\hline & $\mathrm{J}$ & Financial Intermediation \\
\hline & 70 & Real Estate Activities \\
\hline & $71 \mathrm{t} 74$ & Renting of M\&Eq and Other Business Activities \\
\hline & $\mathrm{L}$ & Public Admin and Defence; Compulsory Social Security \\
\hline & M & Education \\
\hline & $\mathrm{N}$ & Health and Social Work \\
\hline & $\mathrm{O}$ & Other Community, Social and Personal Services \\
\hline
\end{tabular}

Fonte: World Input-Output Database (WIOD, 2014) 